\title{
The Influence of Bleached Jute Fiber Filler on the Properties of Vulcanized Natural Rubber
}

\author{
Carla Almeda Correia ${ }^{a}$, Letícia Mota de Oliveira ${ }^{a}$, Ticiane Sanches Valera ${ }^{a}$ *
}

\author{
${ }^{a}$ Departamento de Engenharia Metalúrgica e de Materiais, Universidade de São Paulo, Av. Professor \\ Mello Moraes, 2463, 05508-030, Butantã, SP, Brazil
}

Received: January 18, 2017; Revised: June 22, 2017; Accepted: September 17, 2017

\begin{abstract}
There is growing interest in replacing the synthetic reinforcements used for natural rubber (NR) composites with natural fibers from renewable, environmentally sustainable sources. Jute fibers may be suitable reinforcements for NR because they have a high tensile strength, which is comparable to other fillers such as glass fibers. Thus, we studied the incorporation of bleached jute fibers into NR, characterizing the mechanical, dynamic mechanical, and morphological properties of the composites. The addition of fibers to the NR latex was achieved by chemical coagulation, followed by vulcanization in a laboratory two-roll mixing mill. The elastic modulus at 100 and $300 \%$ elongation of the NR doubled after the addition of $10 \mathrm{phr}$ of fibers without significant loss in the tensile strength or the elongation at break. The hardness was increased by $47 \%$, and the storage modulus also increased, indicating the excellent interactions between the surfaces of the fibers and the NR matrix.
\end{abstract}

Keywords: latex, natural rubber, jute fibers, composites, mechanical properties

\section{Introduction}

Vulcanized natural rubber has several properties that are superior to those of synthetic rubbers, such as high elasticity and high tensile strength ${ }^{1,2}$. Such properties make it an exceptional material for use in several technological products ${ }^{2}$. However, there has been growing interest in the substitution of the synthetic fillers, which are widely used in industrially manufactured rubber composites, by natural fillers that are extracted from a renewable sources because of the sustainability of natural rubber ${ }^{3-5}$.

Natural fibers may be suitable as reinforcements in the natural rubber matrix if they have a tensile strength comparable to those of synthetic fillers, such as glass and carbon fibers ${ }^{1,5}$. Jute fiber is a commercially available and cheap natural fiber; furthermore, it has a high cellulose content $^{6,7}$. To use these lignocellulosic fibers in polymeric composites, removal of the lignin and other amorphous materials is necessary to allow the separation of the fibrils on their structure ${ }^{4,7}$. The most common procedure to remove these materials is alkali treatment using a high-concentration sodium hydroxide solution ${ }^{4,5,8}$. The alkali-treated fibers can be used as reinforcement for different types of polymer composites, such as polypropylene ${ }^{9,10}$, epoxy resin ${ }^{8,11,12}$ and poly (lactic acid) $)^{13,14}$. These studies have shown improvement in the mechanical properties of the polymer matrices with a fiber content of less than $20 \%$.

Natural rubber composites containing natural fibers have been prepared using a variety of methods, for example, using a laboratory two-roll mixing mill ${ }^{15,16}$ and a Brabender batch mixer ${ }^{17}$, and the properties of these composites have

*e-mail: tsvalera@usp.br been analyzed. Pittayavinai et al. ${ }^{15}$ studied the effect of the manipulation of the crosslinking density of the fiber-containing natural rubbers. For some formulations, there was an increase in the tensile strength compared to natural rubber. Formela et $a l .{ }^{17}$ studied the properties of natural rubber and wheat bran biocomposites. This study reported an increase in the tensile modulus with the addition of fillers, explaining that the fibers can cause strain-induced crystallization in natural rubber. The dispersion of the fibers in the composites, however, remains challenging because they tend to agglomerate ${ }^{5}$. For nanoparticle dispersions in natural rubber composites, an effective method for the dispersion of particles in latex has already been demonstrated ${ }^{1,18-20}$.

The objective of this work was to incorporate and disperse treated jute fibers in latex and to evaluate the mechanical, dynamic mechanical, and morphological properties of the vulcanized composite materials.

\section{Materials and Methods}

\subsection{Materials}

High-ammonia natural rubber latex was purchased from BDF Ltda (SP, Brazil), while the raw jute fiber was supplied by Castanhal (PA, Brazil), and the styrene phenol antioxidant oil was supplied from Proquitec Ltda (SP, Brazil).

\subsection{Treatment of the jute fibers}

The jute fibers were milled using a mechanical milling machine with $0.5 \mathrm{~mm}$ sieve opening. The fibers $(30 \mathrm{~g})$ were dispersed in deionized water at $70{ }^{\circ} \mathrm{C}$ and stirred for $3 \mathrm{~h}$ to remove the soluble extractives. The fiber bleaching procedure 
was based on the TAPPI T19m-54 standard method, as described by W. G. Trindade et al. ${ }^{21}$ After washing and filtering, the fibers were dispersed in deionized water at 70 ${ }^{\circ} \mathrm{C}$, and sodium chlorite $(25 \mathrm{~g})$ and glacial acetic acid (10 $\mathrm{mL}$ ) were added to the aqueous suspension. The system was vigorously stirred for $1 \mathrm{~h}$. This procedure was repeated twice, that is, sodium chlorite and glacial acetic acid were added again after a 1-h interval. After the final addition of the reagents, the system was stirred for $3 \mathrm{~h}$. The total reaction time was $5 \mathrm{~h}$. After washing and filtering, the fibers were subjected to an alkaline treatment to remove the acid residues ${ }^{10}$. The fibers were then immersed in a $2 \% \mathrm{NaOH}$ (w/w) solution, stirred at $80{ }^{\circ} \mathrm{C}$ for $2 \mathrm{~h}$, filtered until a $\mathrm{pH}$ of 7 was obtained, and, finally, dried in a vacuum oven at $60{ }^{\circ} \mathrm{C}$ for at least $24 \mathrm{~h}$.

\subsection{Preparation of the $N R /$ bleached jute fibers composites}

The NR/bleached jute fibers (NR-BJF) composites were obtained by mixing an aqueous suspension of treated fibers (2 wt.\%) with NR latex ( $60 \mathrm{wt} . \%$ ) so that the fiber concentrations reached $2.5,5$, and $10 \mathrm{phr}$. The mixtures were dispersed using an Ultra Turrax dispersor (IKA) at 10,000 rpm for $5 \mathrm{~min}$. Coagulation was then performed by adding sufficient acetic acid ( $3 \mathrm{~mol} / \mathrm{L})$ to small latex portions until the solidification of the rubber was complete. Next, the rubbers were immersed in deionized water for five days. The rubber mixtures were prepared in a laboratory two-roll mixing mill. First, the NR was masticated for $5 \mathrm{~min}$, and, then, the components shown in Table 1 were added in the order presented, with mixing times of $5 \mathrm{~min}$ for each material. The samples were then cured at $160^{\circ} \mathrm{C}$ in an electrically heated hydraulic press at $20 \mathrm{MPa}$ for their respective vulcanization times $\left(t_{90}\right)$. These values were determined using an oscillating disc rheometer ODR 2000 (TEAM, Brazil) based on ASTM D-2084-11.

\subsection{Methods}

The X-ray diffraction (XRD) analysis of the raw jute fibers and the treated fibers were performed in an XPERTMPD diffractometer, with $\mathrm{Cu}-K_{\alpha}$ radiation $(\lambda=1.544 \AA)$. The scattered radiation was detected in a $2 \theta$ range of 5 to $40^{\circ}$ at a scanning rate of $0.02 \% \mathrm{~min}$. The crystallinity index (CI) was estimated using Equation $1^{22,23}$, where CI expresses the relative degree of crystallinity, $I_{200}$ the intensity of the peak corresponding to the plane (200), and $I_{\mathrm{am}}$ is the intensity of the diffracted peak at $2 \theta=18^{\circ}$.

$$
\mathrm{CI}(\%)=\frac{I_{200-} I_{\mathrm{am}}}{I_{200}} \times 100
$$

To observe the surface morphology of the raw jute fibers, the treated fibers, the natural rubber, and the fracture surface of the composites, the samples were coated with a thin layer of conductive material (gold) and observed using a fieldemission scanning electron microscope (FEI, INSPECT F50 SEM-FEG) at an applied accelerating voltage of $15 \mathrm{kV}$.
Table 1. Basic formulation of natural rubber compounds.

\begin{tabular}{cc}
\hline Material & Parts \\
\hline Natural rubber & 100 \\
Bleached jute fibers $^{c}$ & $0-10$ \\
Antioxidant oil $^{\mathrm{a}}$ & 1.5 \\
Zinc oxide $^{\text {Stearic acid }}$ & 4 \\
M.B.T.S. $^{\mathrm{b}}$ & 1 \\
T.M.T.D. $^{\mathrm{c}}$ & 1 \\
Sulfur & 0.5 \\
\hline
\end{tabular}

\section{${ }^{a}$ Styrene Phenol}

b 2,2' Dibenzothiazyl Disulfide

${ }^{c}$ Tetramethylthiuram Disulfide

The NR composite samples were cryogenically fractured. The sample hardness was determined using a Shore A-type durometer. Compound samples (6-mm thick) were used to carry out measurements. Tensile tests were performed based on the ASTM D412-15a standard on a universal testing machine (Alpha Technologies, T2000) fitted with a contact-style extensometer. A crosshead speed of $500 \mathrm{~mm} /$ min and $1 \mathrm{kN}$ load cell were used.

Dynamic mechanical thermal analysis (DMTA) was performed on a DMTA instrument (DMA 800, PerkinElmer) using rectangular samples with dimensions of $12 \times 8.5 \times$ $2.1 \mathrm{~mm}$. The experiment was carried out at a frequency of $1 \mathrm{~Hz}$ from -100 to $-12^{\circ} \mathrm{C}$ at a heating rate of $2^{\circ} \mathrm{C} / \mathrm{min}$ and an oscillation amplitude of $50 \mu \mathrm{m}$.

\section{Results and Discussion}

\subsection{X-ray diffraction of fibers}

The X-ray diffraction curves of raw and treated jute fibers are shown in Figure 1. Peaks at approximately $2 \theta$ $=16,22$, and $34.5^{\circ}$ arise from the cellulose (110), (200), and (004) planes, respectively. This indicates the presence of type I cellulose in the fibers, both before and after bleaching treatment ${ }^{23-25}$. The increase in the peak intensity of the (200) reflections indicates that the crystallinity has increased. Furthermore, the small change in $2 \theta$ from 22.1 to $22.4^{\circ}$ indicates the transformation of cellulose $\mathrm{I}_{\beta}$ into cellulose $\mathrm{I}_{\alpha}$, promoted by the alkali treatment; this occurs even at low concentrations of $\mathrm{NaOH}$, such as that used in this work. Such transformations have also been reported in the literature ${ }^{25,26}$. The crystallinity indices for the raw and treated fibers were 58 and $66 \%$, respectively. The results confirm the increase in the crystallinity of the jute fibers after the bleaching process, which may contribute to its applications in polymer composites ${ }^{8,27,28}$.

\subsection{Surface morphology of the fibers}

Figure 2 shows SEM micrographs obtained for the fibers, both raw and after the chemical treatment. The SEM 


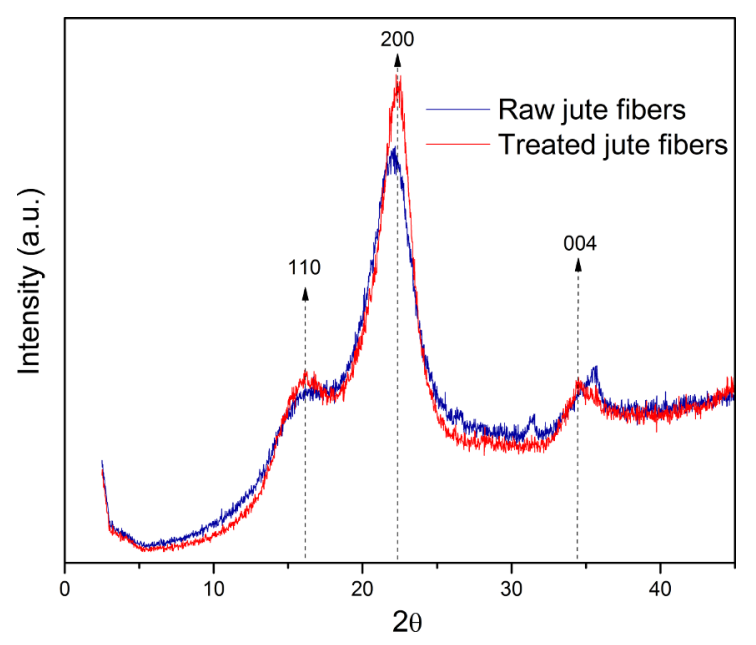

Figure 1. X-ray diffraction curves of raw and treated jute fibers.

micrographs show the differences in the fiber surfaces by comparing images taken before and after the bleaching process. The surfaces of the treated fibers are smoother and contain fewer solid aggregates when compared to the surface of the raw fibers. Furthermore, the treated fibers show less agglomeration, which may indicate that the bleaching treatment was able to remove a significant amount of the amorphous mass from the fiber surfaces, such as lignin, impurities, and low molar mass polysaccharides, as has also been previously reported ${ }^{23,29,30}$.

\subsection{Vulcanizing behavior}

The vulcanizing behavior of the investigated compounds is presented in Table 2. As expected, the addition of fibers to NR increases the minimum $\left(M_{\mathrm{L}}\right)$ and maximum torque $\left(M_{\mathrm{H}}\right)$ values of the composites. The vulcanization times obtained for all compositions were similar. As reported ${ }^{15,17,31}$, the torque values of natural rubber increased with the fiber addition,
Table 2. Vulcanizing behavior of the compounds at $160^{\circ} \mathrm{C}$.

\begin{tabular}{cccc}
\hline Sample & $\left.\mathbf{M}_{\mathbf{L}} \mathbf{( d N m}\right)$ & $\mathbf{M}_{\mathbf{H}}(\mathbf{d N m})$ & $\mathbf{t}_{\mathbf{9} \mathbf{0}}(\mathbf{m i n})$ \\
\hline $\mathrm{NR}$ & 2.4 & 18.6 & 6.22 \\
$\mathrm{NR}+2.5 \mathrm{BJF}$ & 3.6 & 23.7 & 6.67 \\
$\mathrm{NR}+5 \mathrm{BJF}$ & 3.9 & 24.6 & 6.93 \\
$\mathrm{NR}+10 \mathrm{BJF}$ & 4.2 & 24.8 & 6.52 \\
\hline
\end{tabular}

indicating an increase in the stiffness of the vulcanized compounds. This is due to the restriction in the mobility of the rubber molecules caused by the fibers ${ }^{31}$. However, studies have shown ${ }^{17,31}$ that the insertion of fibers generally decreases the vulcanization times of the rubber composites. That is because, when fibers are added during processing, the mixing time must be increased to obtain adequate homogeneity. Thus, there is an increase in temperature that favors the prevulcanization reactions on the mills ${ }^{17,31}$. In this work, because the fibers were added during the coagulation step, a decrease in $t_{90}$ was not observed. The $t_{90}$ values obtained in this test were used for the vulcanization of the composites produced in this work.

\subsection{Hardness}

Table 3 lists the hardness values of the samples. As expected, the hardness of the composites increased with increasing NR fiber content. Studies ${ }^{15,32}$ have reported that the addition of fibers causes a significant increase in the hardness of natural rubber. This is typical of traditional composites, confirming the increase in the stiffness of the compounds. ${ }^{17}$

\subsection{Mechanical properties}

The mechanical properties of bleached jute fibers and NRbased composites are presented in Table 3. A slight decrease in the tensile strength, from 17 to $15 \mathrm{MPa}$, was observed on the addition of $10 \mathrm{phr}$ of fibers to the natural rubber. Other
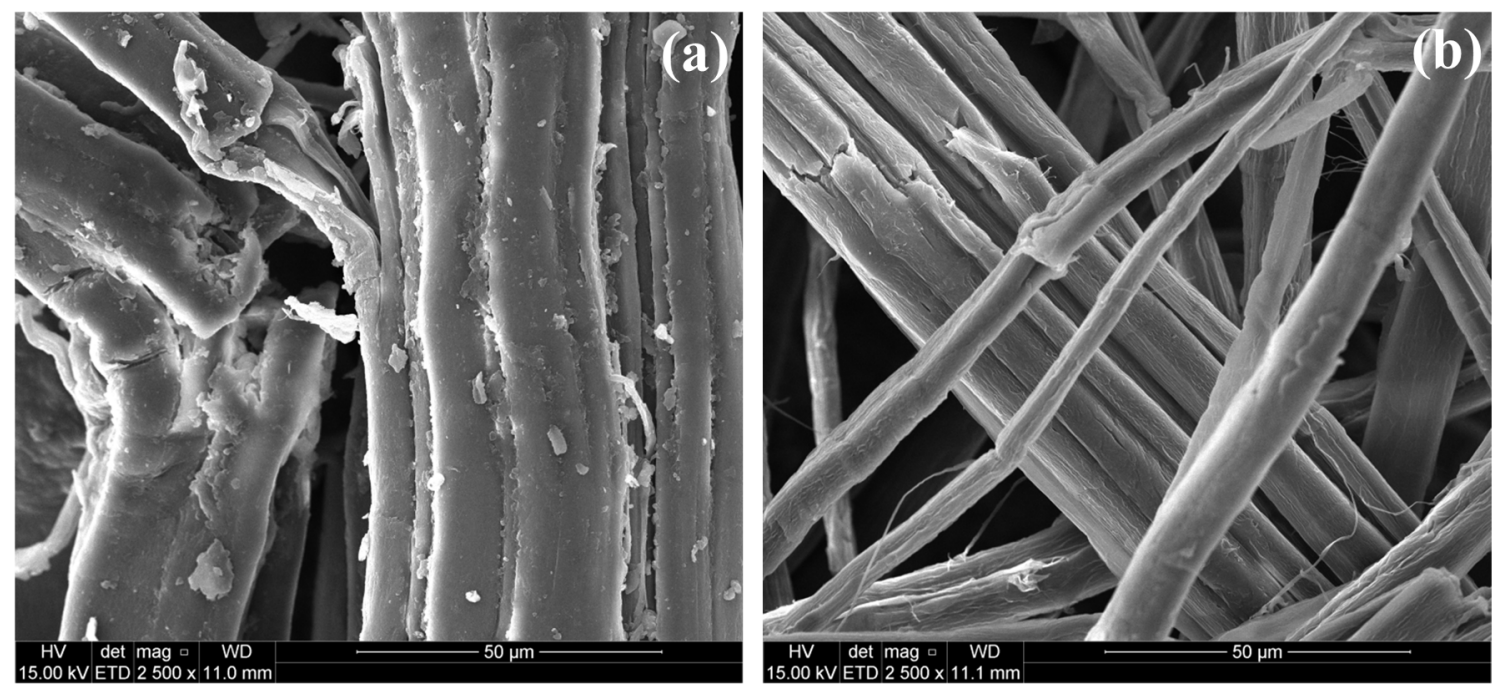

Figure 2. SEM micrograph $(\mathrm{x} 2,500)$ of raw (a) and bleached (b) jute fibers. 
Table 3. Mechanical properties of the samples.

\begin{tabular}{cccccc}
\hline Sample & Tensile strength (MPa) & Elongation at break (\%) & $\mathbf{M}_{\mathbf{1 0 0}}(\mathbf{M P a})$ & $\mathbf{M}_{\mathbf{3 0 0}}(\mathbf{M P a})$ & Hardness (shore-A) \\
\hline NR & $17 \pm 2$ & $692 \pm 33$ & $0.78 \pm 0.07$ & $1.68 \pm 0.11$ & $37.3 \pm 0.3$ \\
$\mathrm{NR}+2.5 \mathrm{BJF}$ & $17 \pm 1$ & $715 \pm 23$ & $1.13 \pm 0.06$ & $1.90 \pm 0.05$ & $43.2 \pm 0.6$ \\
$\mathrm{NR}+5 \mathrm{BJF}$ & $18 \pm 2$ & $692 \pm 15$ & $1.47 \pm 0.05$ & $2.19 \pm 0.05$ & $51.3 \pm 0.3$ \\
$\mathrm{NR}+10 \mathrm{BJF}$ & $15 \pm 1$ & $691 \pm 15$ & $2.10 \pm 0.1$ & $2.60 \pm 0.10$ & \pm 0.5 \\
\hline
\end{tabular}

studies ${ }^{31-33}$ have also shown a reduction in both the tensile strength and elongation at break when raw and treated natural fibers were added to natural rubber. However, in this work, the values of elongation at break were not affected by the increasing quantity of fibers.

The values of the elastic modulus at 100 and $300 \%$ elongation $\left(\mathrm{M}_{100}\right.$ and $\left.\mathrm{M}_{300}\right)$ underwent a slight increase on the addition of fibers, indicating that the fibers increased the stiffness of the natural rubber $^{32}$. These results corroborate those reported in the literature ${ }^{32,34}$, which indicate that the use of natural fibers as a reinforcement in natural rubber matrices increases the tensile modulus; this may be indicative of the excellent interactions between the fiber surface and the natural rubber matrix. ${ }^{32,33}$

\subsection{Dynamic mechanical thermal analysis (DMTA)}

The storage moduli for natural rubber and the composites are shown in Figure 3. An increase in modulus was observed with increasing fiber content. Similar studies ${ }^{9,35,36}$ have reported that an increase in fiber content increases the storage modulus of the polymer matrix. This effect was more pronounced for the addition of $5 \mathrm{phr}$ jute fibers, and the addition of $2.5 \mathrm{phr}$ practically did not increase the storage modulus. The DMTA results corroborate those obtained for the tensile modulus and, again, indicate that the addition of fibers contributed to the increasing stiffness of the NR.

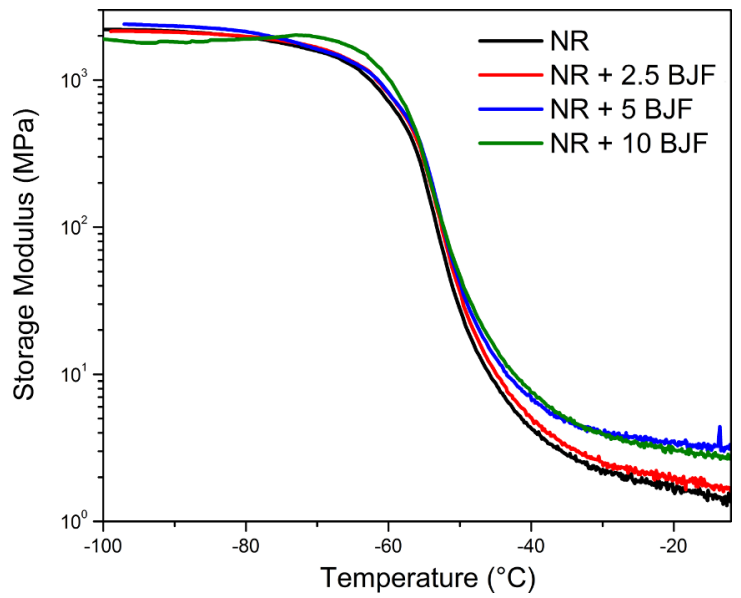

Figure 3. Storage Modulus versus temperature for NR composites.
Figure 4 shows the mechanical loss factor (tan delta) curves for the NR composites. A decrease in the tan delta peak was noted as the fiber amount increased. This occurs because of the decrease in the mobility of the polymer chains on the addition of the fibers. This trend suggests that fibers and the natural rubber matrix have a strong interfacial adhesion ${ }^{36,37}$. On the other hand, based on the tan delta curves, it was also possible to determine the glass transition temperature $\left(T_{\mathrm{g}}\right)$ of the compositions, which were $-50.5,-49.8,-50.6$, and $-50.4{ }^{\circ} \mathrm{C}$, for natural rubber and the composites with 2.5 , 5 , and $10 \mathrm{phr}$ fibers content, respectively. The presence of fibers did not significantly alter the $T_{\mathrm{g}}$ of the natural rubber.

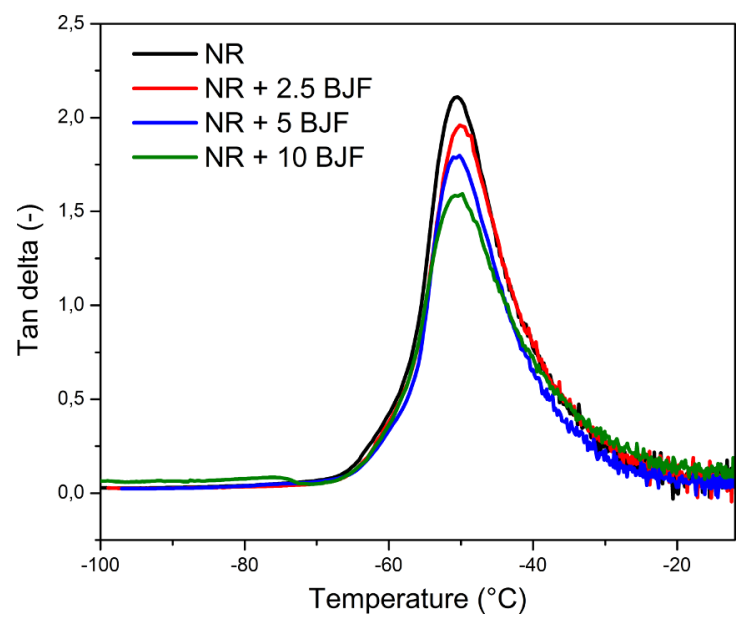

Figure 4. Tan delta versus temperature for NR composites.

\subsection{Morphology of the NR composites}

Figure 5 shows the SEM images for NR and for composites with 5 and $10 \mathrm{phr}$ of fibers. As the fiber content increased, the number of particles dispersed in the matrix increased. The pure NR sample contains particles related to the vulcanization additives, which are smaller in size than the fibers indicated by red arrows in Figures 5b, 5c and 5d. Cavities (yellow arrows), which are probably related to the pullout of fibers during the cryogenic rupture of the sample, are also visible. Compared to the particulate dispersions observed in similar studies ${ }^{12,32}$, those of the composites presented here are finer, indicating that the method of fiber incorporation into NR was efficient. 

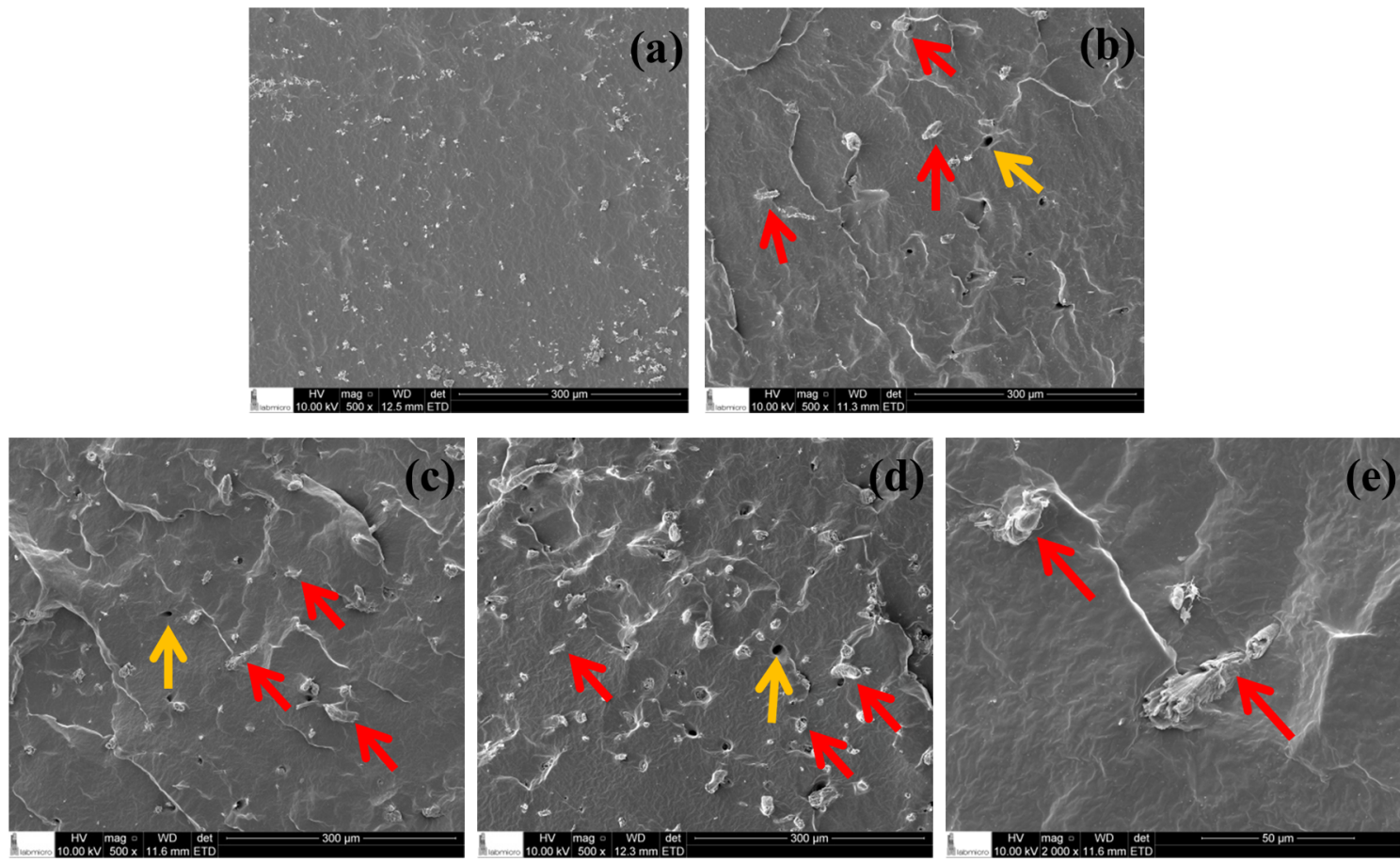

Figure 5. SEM images of: (a) NR, (b) NR with $2.5 \mathrm{phr}$, (c and e) NR with $5 \mathrm{phr}$ and (d) $10 \mathrm{phr}$ of fibers.

\section{Conclusions}

The morphological analysis of the jute fibers indicated that the bleaching process was satisfactory because the solids were removed from the surface. Using XRD analysis, we found that the treated fibers showed higher crystallinity than the raw jute fibers, confirming that the treatment removed some of the amorphous cellulosic fibers. The composites were obtained by incorporating the bleached fibers into the latex, followed by processing in a two-roll mixing mill. Using tensile and DMTA analysis, we found an increase in the storage modulus and in the elastic modulus at 100 and $300 \%$ elongation on the addition of fibers to the NR, indicating the increased stiffness of the natural rubber. Morphological analysis of the composites showed that there was a fine dispersion of the fillers, which may indicate strong interactions between the fiber surfaces and the natural rubber matrix. This study showed that the method of incorporating fibers into latex is efficient, resulting in natural rubber composites with good properties.

\section{Acknowledgements}

The authors would like to thank Castanhal for providing the jute fibers, Proquitec for providing the antioxidant oil, and $\mathrm{CNPq}$ and CAPES for their financial support.

\section{References}

1. Sajithkumar KJ, Visakh PM, Ramasamy EV. Moringa oleifera (Drum Stick Vegetable Fibre) Based Nanocomposites with Natural Rubber: Preparation and Characterizations. Waste and Biomass Valorization. 2016;7(5):1227-1234.

2. Katzenberg F, Tiller JC. Shape memory natural rubber. Journal of Polymer Science Part B: Polymer Physics. 2016;54(14):13811388.

3. Khan RA, Khan MA, Zaman HU, Pervin S, Khan N, Sultana S, et al. Comparative Studies of Mechanical and Interfacial Properties Between Jute and E-Glass Fiber-reinforced Polypropylene Composites. Journal of Reinforced Plastics and Composites. 2009;29(7):1078-1088.

4. Silva R, Haraguchi SK, Muniz EC, Rubira AF. Aplicações de fibras lignocelulósicas na química de polímeros e em compósitos. Química Nova. 2009;32(3):661-671.

5. Zhou Y, Fan M, Chen L. Interface and bonding mechanisms of plant fibre composites: An overview. Composites Part B: Engineering. 2016;101:31-45.

6. Zaman HU, Khan RA, Haque ME, Khan MA, Khan A, Huq T, et al. Preparation and mechanical characterization of jute reinforced polypropylene/natural rubber composite. Journal of Reinforced Plastics and Composites. 2010;29(20):3064-3065.

7. Mohanty AK, Misra M, Drzal LT, eds. Natural Fibers, Biopolymers, and Biocomposites. Boca Raton: CRC Press; 2005. 
8. Somashekar S, Shanthakumar GC. Effect of alkali treatment on mechanical properties of sisal-reinforced epoxy polymer matrix composite. International Journal of Mechanical Engineering and Robotics Research. 2014;3(4):441-450.

9. Marques MFV, Melo RP, Araujo RS, Lunz JN, Aguiar VO. Improvement of mechanical properties of natural fiberpolypropylene composites using successive alkaline treatments. Journal of Applied Polymer Science. 2015;132(12):41710.

10. Han HC, Gong XL. One-step green treatment of hemp fiber used in polypropylene composites. Polymer Composites. 2016;37(2):385-390.

11. Patel JP, Parsania PH. Fabrication and comparative mechanical, electrical and water absorption characteristic properties of multifunctional epoxy resin of bisphenol-C and commercial epoxy-treated and -untreated jute fiber-reinforced composites. Polymer Bulletin. 2016;74(2):485-504.

12. Cai M, Takagi H, Nakagaito AN, Li Y, Waterhouse GIN. Effect of alkali treatment on interfacial bonding in abaca fiberreinforced composites. Composites Part A: Applied Science and Manufacturing. 2016;90:589-597.

13. Gunti R, Prasad AVR, Gupta AVSSKS. Mechanical and degradation properties of natural fiber reinforced PLA composites: Jute, sisal, and elephant grass. Polymer Composites. 2016. DOI: $10.1002 /$ pc.24041 [e-pub ahead of print]

14. Rajesh G, Prasad AVR, Gupta AVSSKS. Mechanical and degradation properties of successive alkali treated completely biodegradable sisal fiber reinforced poly lactic acid composites. Journal of Reinforced Plastics and Composites. 2015;34(12):951961.

15. Pittayavinai $P$, Thanawan $S$, Amornsakchai T. Manipulation of mechanical properties of short pineapple leaf fiber reinforced natural rubber composites through variations in cross-link density and carbon black loading. Polymer Testing. 2016;54:84-89.

16. $\mathrm{Xu} \mathrm{ZH,} \mathrm{Kong} \mathrm{ZN.} \mathrm{Mechanical} \mathrm{and} \mathrm{thermal} \mathrm{properties} \mathrm{of} \mathrm{short-}$ coir-fiber-reinforced natural rubber/polyethylene composites. Mechanics of Composite Materials. 2014;50(3):353-358.

17. Formela K, Hejna A, Piszczyk Ł, Saeb MR, Colom X. Processing and structure-property relationships of natural rubber/wheat bran biocomposites. Cellulose. 2016;23(5):3157-3175.

18. Swapna VP, Stephen R, Greeshma T, Dev SC, Sreekala MS. Mechanical and swelling behavior of green nanocomposites of natural rubber latex and tubular shaped halloysite nano clay. Polymer Composites. 2016;37(2):602-611.

19. Ruamcharoen J, Ratana T, Ruamcharoen P. Bentonite as a reinforcing and compatibilizing filler for natural rubber and polystyrene blends in latex stage. Polymer Engineering \& Science. 2014;54(6):1436-1443.

20. Amarasiri A, Ratnayake UN, Silva UK, Walpalage S, Siriwardene S. Natural rubber latex-clay nanocomposite: use of montmorillonite clay as an alternative for conventional $\mathrm{CaCO}_{3}$ Journal of the National Science Foundation of Sri Lanka. 2013;41(4):293-302.

21. Trindade WG, Hoareau W, Megiatto JD, Razera IAT, Castellan A, Frollini E. Thermoset phenolic matrices reinforced with unmodified and surface-grafted furfuryl alcohol sugar cane bagasse and curaua fibers: properties of fibers and composites. Biomacromolecules. 2005;6(5):2485-2496.
22. Segal L, Creely JJ, Martin AE, Conrad CM. An Empirical Method for Estimating the Degree of Crystallinity of Native Cellulose Using the X-Ray Diffractometer. Textile Research Journal. 1959;29(10):786-794.

23. César NR, Pereira-da-Silva MA, Botaro VR, Menezes AJ. Cellulose nanocrystals from natural fiber of the macrophyte Typha domingensis: extraction and characterization. Cellulose. 2015;22(1):449-460.

24. French AD. Idealized powder diffraction patterns for cellulose polymorphs. Cellulose. 2014;21(2):885-896.

25. Kasyapi N, Chaudhary V, Bhowmick AK. Bionanowhiskers from jute: Preparation and characterization. Carbohydrate Polymers. 2013;92(2):1116-1123.

26. Sulyanov SN, Kheiker DM, Vainshtein DI, den Hartog HW. Characterization of $\mathrm{Na}$ precipitates in electron irradiated $\mathrm{NaCl}$ crystals by wide-angle X-ray scattering (WAXS). Solid State Communications. 2003;128(11):419-423.

27. Siqueira G, Bras J, Dufresne A. Cellulosic Bionanocomposites: A Review of Preparation, Properties and Applications. Polymers. 2010;2(4):728-765.

28. John MJ, Thomas S. Biofibres and biocomposites. Carbohydrate Polymers. 2008;71(3):343-364.

29. Khan GMA, Shaheruzzaman M, Rahman MH, Razzaque SMA, Islam MS, Alam MS. Surface modification of okra bast fiber and its physico-chemical characteristics. Fibers and Polymers. 2009;10(1):65-70.

30. Gültekin BC. Bleaching of SeaCell(r) active fabrics with hydrogen peroxide. Fibers and Polymers. 2016;17(8):11751180 .

31. Lopattananon N, Panawarangkul K, Sahakaro K, Ellis B. Performance of pineapple leaf fiber-natural rubber composites: The effect of fiber surface treatments. Journal of Applied Polymer Science. 2006;102(2):1974-1984.

32. Datta J, Włoch M. Preparation, morphology and properties of natural rubber composites filled with untreated short jute fibres. Polymer Bulletin. 2016;74(3):763-782.

33. Mathew L, Joseph R. Mechanical properties of short-isora-fiberreinforced natural rubber composites: Effects of fiber length, orientation, and loading; alkali treatment; and bonding agent. Journal of Applied Polymer Science. 2007;103(3):1640-1650.

34. De D, De D, Adhikari B. The effect of grass fiber filler on curing characteristics and mechanical properties of natural rubber. Polymers for Advanced Technologies. 2004;15(12):708-715.

35. Hintze C, Stoček R, Horst T, Jurk R, Wiessner S, Heinrich G. Dynamic behavior of short aramid fiber-filled elastomer composites. Polymer Engineering \& Science. 2014;54(12):29582964.

36. Portella EH, Romanzini D, Angrizani CC, Amico SC, Zattera AJ. Influence of Stacking Sequence on the Mechanical and Dynamic Mechanical Properties of Cotton/Glass Fiber Reinforced Polyester Composites. Materials Research. 2016;19(3):542-547.

37. Pothan LA, Oommen Z, Thomas S. Dynamic mechanical analysis of banana fiber reinforced polyester composites. Composites Science and Technology. 2002;63(2):283-293. 